\title{
Significance of a Family-based Study of Hereditary Thrombosis: A Single-family Case Series of Protein C Deficiency
}

\author{
Mayuri Ichinose ${ }^{1}$, Kenji Kasai ${ }^{2}$, Yuzo Kayamori ${ }^{3}$ and Naotaka Hamasaki ${ }^{4}$
}

\begin{abstract}
:
Thrombophilia is a serious unpredictable complication caused by gene mutations, resulting in anticoagulant deficiencies. We herein report a single-family case series of protein C (PC) deficiency. Case 1 involved a Japanese man whose PC deficiency resulted in severe systemic thrombosis. The patients in cases 2 and 3 were his daughters who were diagnosed with PC deficiency via carrier screening in 2001 and later both became pregnant. Owing to appropriate treatments during pregnancy, they did not develop thrombosis and safely gave birth to healthy infants. This family case series suggests that appropriate knowledge concerning thrombophilia helps prevent future emergencies.
\end{abstract}

Key words: protein $\mathrm{C}$ deficiency, hereditary thrombophilia, single family

(Intern Med 58: 1923-1928, 2019)

(DOI: 10.2169/internalmedicine.2308-18)

\section{Introduction}

Owing to the information and techniques generated by the Human Genome Project, it is now possible to determine the risk for future illnesses and the genetic characteristics and idiosyncrasies of families and ethnicities (1). However, the management of genetic information and its use in medical contexts have raised societal concerns $(2,3)$.

In adults, thrombosis is thought to mainly result from non-genetic factors, such as obesity, cigarette smoking, surgery, cancer, and pregnancy (4). Protein C (PC), protein S (PS), and antithrombin III (AT-III) deficiencies are also risk factors for thrombosis and have been linked to infertility $(5,6)$. However, the levels of these anticoagulants are only measured in special circumstances and not in routine checkups. Recent studies on PC, PS, and AT-III deficiencies underscore the importance of carrier screening for congenital thrombosis in several clinical fields, including obstetrics/ gynecology, pediatrics, and internal medicine (7). These studies were performed not only in the US and Europe but also in Japan, where anticoagulant deficiencies have been reported to be the cause of thrombotic conditions in approximately $65 \%$ of cases (8-10). They also established the validity of screening for hereditary thrombosis and other thrombophilia-related disorders.

Sixteen years ago, we encountered several patients of a single family who had severe systemic thrombosis caused by PC deficiency. Owing to its severity, we performed carrier screenings to determine the factors that predisposed them to thrombosis. Three generations of this family were screened, and three of its members (namely, the first family member to be diagnosed with PC deficiency and his two daughters), all with PC deficiency, are described in the present report.

\section{Case Reports}

Fig. 1 shows the family pedigree and indicates which family members were PC-deficient, as indicated by their coagulation profiles. This study was approved by the Institutional Review Board of Fuji City General Hospital. Informed consent was obtained from all participants before ge-

${ }^{1}$ Division of Nephrology and Hypertension, Department of Internal Medicine, Jikei University School of Medicine, Japan, ${ }^{2}$ Department of Internal Medicine, Fuji City General Hospital, Japan, ${ }^{3}$ Department of Health Sciences, Faculty of Medical Sciences, Kyushu University, Japan and ${ }^{4}$ Faculty of Medical Sciences, Kyushu University, Japan

Received: November 7, 2018; Accepted: January 8, 2019; Advance Publication by J-STAGE: March 28, 2019

Correspondence to Dr. Mayuri Ichinose, michinose@jikei.ac.jp 


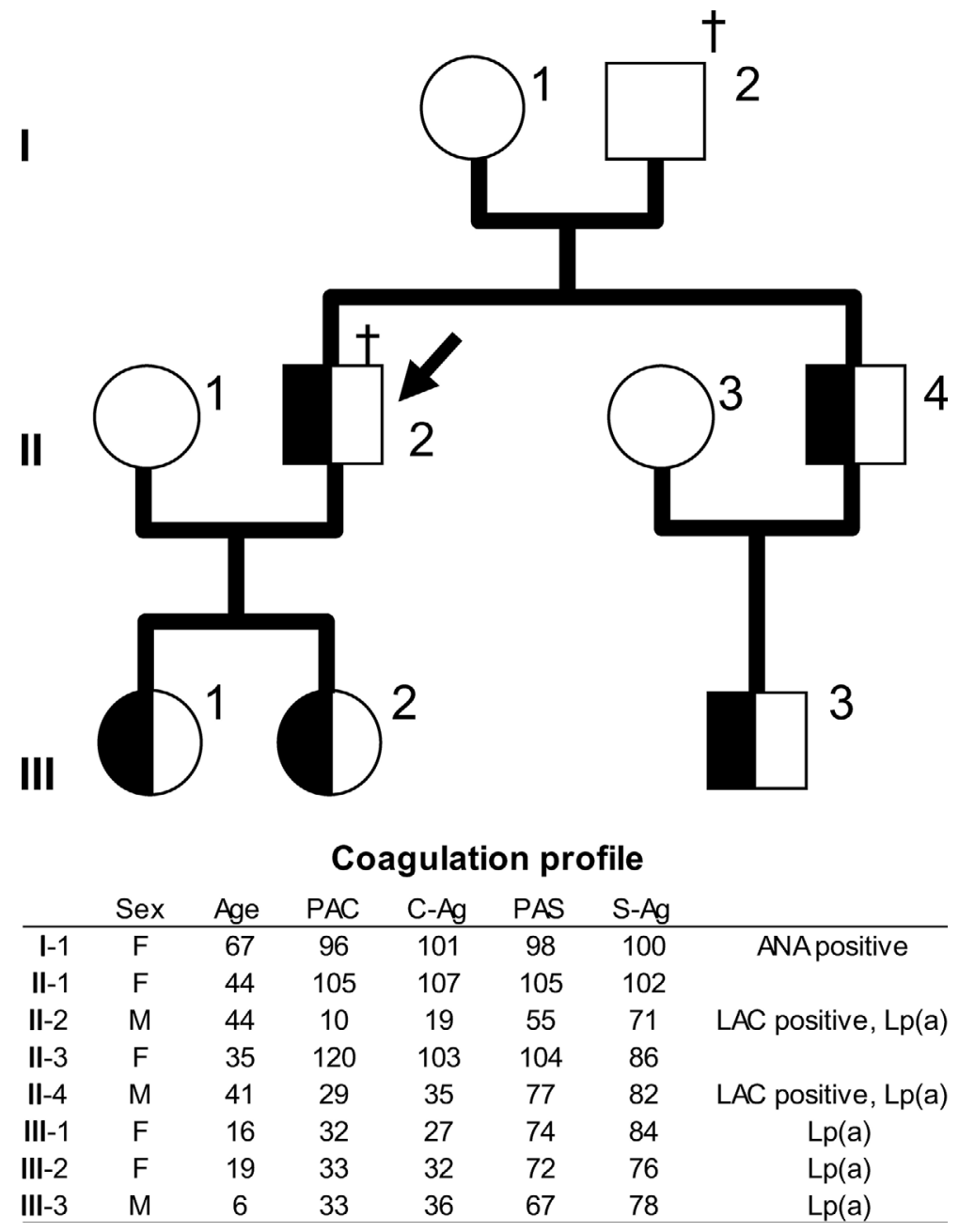

Figure 1. The family pedigree and coagulation profiles in 2001. The arrow indicates the proband. The half-solid boxes represent the men (squares) and women (circles) with heterozygous protein $\mathrm{C}$ deficiency. $\uparrow:$ deceased, ANA: antinuclear antibody, $C$-Ag: protein $C$ antigen, LAC: lupus anticoagulant, Lp (a): lipoprotein (a), PAC: protein $\mathrm{C}$ activity, PAS: protein $\mathrm{S}$ activity, $\mathrm{S}$-Ag: protein $\mathrm{S}$ antigen

netic screening.

\section{Case 1}

The person who led to the carrier screening of his family members was a 41-year-old Japanese man (Fig. 1, II-2). His initial symptom, appearing in October 1997, was intermittent injury-related claudication in the right lower leg, and the diagnosis was Buerger's disease. Owing to severe lower left abdominal pain in January 2001, he was admitted to Fuji City Hospital on an emergency basis. His family's medical history included a brother (Fig. 1, II-4) who had a cerebrovascular infarction when he was 30 years old; the brother was prescribed the anticoagulant warfarin by the Department of Neurosurgery, and no further infarctions occurred.

The physiological findings of patient II-2 at the time of admission were as follows: height, $173 \mathrm{~cm}$; weight, $64 \mathrm{~kg}$; blood pressure, 144/60 $\mathrm{mmHg}$; heart rate, 72 beats per minute and stable; body temperature, $37^{\circ} \mathrm{C}$; consciousness, clear and lucid; respiratory status, eupnea; and heart sounds, clear. Additional observations included abdominal and bowel hy- perperistalsis and tenderness in the lower left abdominal region. No peritoneal irritation symptoms, neurological abnormalities, or (as assessed via radiography) abdominal abnormalities were noted. The results of blood biochemistry tests were normal (Table 1). Based on the results of contrast radiography, patient II-2 was diagnosed with partial renal infarction, which was treated via continuous intravenous heparin (anticoagulant) drip infusion immediately after hospitalization.

On the third day of hospitalization, patient II-2 experienced loss of vision in his right eye and developed left paraplegia. His visual acuity (VA) score was $\leq 0.01$ in the right eye and 0.9 in the left eye. A close examination showed total occlusion of the right ophthalmic artery (Fig. 2). Highresolution ultrasonography revealed equivalent levels of echogenicity and equivalent levels of mobility in the left internal and external carotid arteries (Fig. 3). Brain magnetic resonance imaging including angiography showed absence of abnormalities. The paralysis disappeared after a few days, but the VA of the patient's right eye remained low.

A coagulation test to determine the risk factors for throm- 
Table 1. Blood Biochemical Test Results of Case 1 (on Admission).

\begin{tabular}{lclcll}
\hline WBC & $11,300 / \mu \mathrm{L}$ & $\mathrm{TP}$ & $7.3 \mathrm{~g} / \mathrm{dL}$ & Urinalysis & \\
$\mathrm{RBC}$ & $4.64 \times 10^{6}$ & $\mathrm{Alb}$ & $3.8 \mathrm{~g} / \mathrm{dL}$ & & \\
$\mathrm{Hgb}$ & $14.6 \mathrm{~g} / \mathrm{dL}$ & $\mathrm{Na}$ & $138 \mathrm{mmol} / \mathrm{L}$ & Specific gravity & 1.007 \\
$\mathrm{Hct}$ & $44.5 \%$ & $\mathrm{~K}$ & $4.1 \mathrm{mmol} / \mathrm{L}$ & $\mathrm{PH}$ & 7.1 \\
$\mathrm{MCV}$ & 95 & $\mathrm{CL}$ & $104 \mathrm{mmol} / \mathrm{L}$ & Urine protein & $(+)$ \\
$\mathrm{MCH}$ & 31 & $\mathrm{BUN}$ & $12 \mathrm{mg} / \mathrm{dL}$ & Urine sugar & $(-)$ \\
$\mathrm{MCHC}$ & 32 & $\mathrm{CRE}$ & $0.7 \mathrm{mg} / \mathrm{dL}$ & Ketone body & $(2+)$ \\
$\mathrm{PLT}$ & $25.7 \times 10^{3}$ & $\mathrm{UA}$ & $9.5 \mathrm{mg} / \mathrm{dL}$ & Hematuria & $(-)$ \\
& & $\mathrm{Ca}$ & $9.3 \mathrm{mg} / \mathrm{dL}$ & Sediment & \\
GOT & $20 \mathrm{IU} / \mathrm{L}$ & Pi & $2.4 \mathrm{mg} / \mathrm{dL}$ & RBC & $1-4 / \mathrm{F}$ \\
GPT & $20 \mathrm{IU} / \mathrm{L}$ & $\mathrm{T}-\mathrm{Cho}$ & $144 \mathrm{mg} / \mathrm{dL}$ & WBC & $1-4 / \mathrm{F}$ \\
ALP & $248 \mathrm{IU} / \mathrm{L}$ & TG & $146 \mathrm{mg} / \mathrm{dL}$ & & \\
LDH & $209 \mathrm{IU} / \mathrm{L}$ & Amy & $98 \mathrm{mg} / \mathrm{L}$ & & \\
CPK & $94 \mathrm{IU} / \mathrm{L}$ & CRP & $1.6 \mathrm{mg} / \mathrm{dL}$ & & \\
ZTT & $5.5 \mathrm{IU} / \mathrm{L}$ & Blood sugar & $89 \mathrm{mg} / \mathrm{dL}$ & & \\
LAP & $36 \mathrm{IU} / \mathrm{L}$ & & & & \\
$\gamma$ GTP & $65 \mathrm{IU} / \mathrm{L}$ & CCr & $62 \mathrm{~mL} / \mathrm{min}$ & & \\
CHE & $188 \mathrm{IU} / \mathrm{L}$ & Urine Prot. & $0.2 \mathrm{~g} / \mathrm{day}$ & & \\
T-Bil & $0.5 \mathrm{mg} / \mathrm{dL}$ & U-NAG & $3.4 \mathrm{U} / \mathrm{L}$ & & \\
D-Bil & $0.1 \mathrm{mg} / \mathrm{dL}$ & & & & \\
\hline
\end{tabular}

WBC: white blood cell, RBC: red blood cell, Hb: hemoglobin, MCHC: mean corpuscular hemoglobin concentration, MCV: mean corpuscular volume, Ht: hematocrit, Plt: platelet count, GOT: glutamate oxaloacetate transaminase, GPT: glutamic pyruvic transaminase, LDH: lactate dehydrogenase, CPK: creatine phosphokinase, ZTT: zinc sulfate turbidity test, LAP: leucine aminopeptidase, $\gamma$ GTP: $\gamma$ - glutamyltransferase, Che: cholinesterase, T-Bil: total bilirubin, D-Bil: direct bilirubin, TP: serum creatinine, Alb: serum albumin, Na: serum sodium, K: serum potassium, CL: serum chlorine, BUN: blood urea nitrogen, UA: serum uric acid, T-Cho: total cholesterol, TG: triglyceride, Amy: amylase, CRP: Creactive protein, $\mathrm{CCr}$ : creatinine clearance

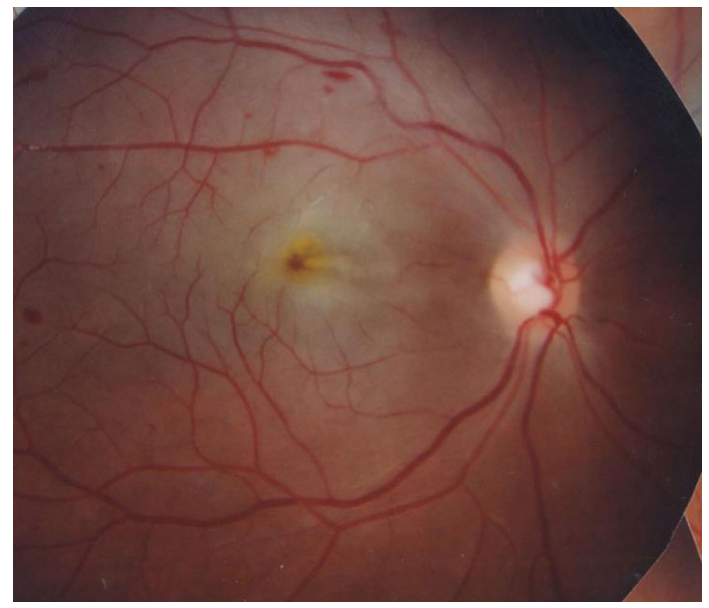

Figure 2. Photograph of the fundus of the right eye showing total occlusion of the retinal artery.

bosis confirmed the diagnosis of severe thrombosis caused by PC deficiency (Table 2). Furthermore, the patient's thrombosis was complicated by an immune system dysfunction (antiphospholipid antibody syndrome). Following intensive anticoagulant treatment, patient II-2's condition stabilized for a short time. However, he subsequently developed an infarction in the small intestine due to mesenteric arterial thrombosis. The infarction caused a perforation in the small intestine, which led to widespread peritonitis.
Patient II-2 passed away on January 2002. An autopsy was conducted after receiving written consent from his family. The autopsy revealed the cause of death to be widespread peritonitis. Remarkable systemic occlusion of the peripheral arteries and veins was observed, despite the lack of thrombus formation within the cardiovascular system.

Four additional family members (Fig. 1; II-2, III-1, III-2, and III-3) were diagnosed with familial PC deficiency. A DNA sequencing analysis identified a heterozygous mutation in exon 8 of the PROC gene (which encodes PC) in all five PC-deficient family members. Specifically, CTT (leucine) was replaced by TTT (phenylalanine) at codon 223.

\section{Case 2}

Patient III-1 (Fig. 1) was diagnosed as PC-deficient in 2001. She visited our hospital in January 2003, at which time she was 19 years old and 5 weeks pregnant. Following discussions between the obstetrician in charge and members of the Internal Medicine Department at our hospital, she received subcutaneous injections of danaparoid sodium as an anticoagulant therapy. At this time, this drug was not covered by the Japanese health insurance system for treatment of thrombosis-related infertility. Therefore, it was administered after explaining its risks, therapeutic effects, and high cost and obtaining written informed consent from the patient and her family.

The dosing regimen of danaparoid was 1,250 units every 


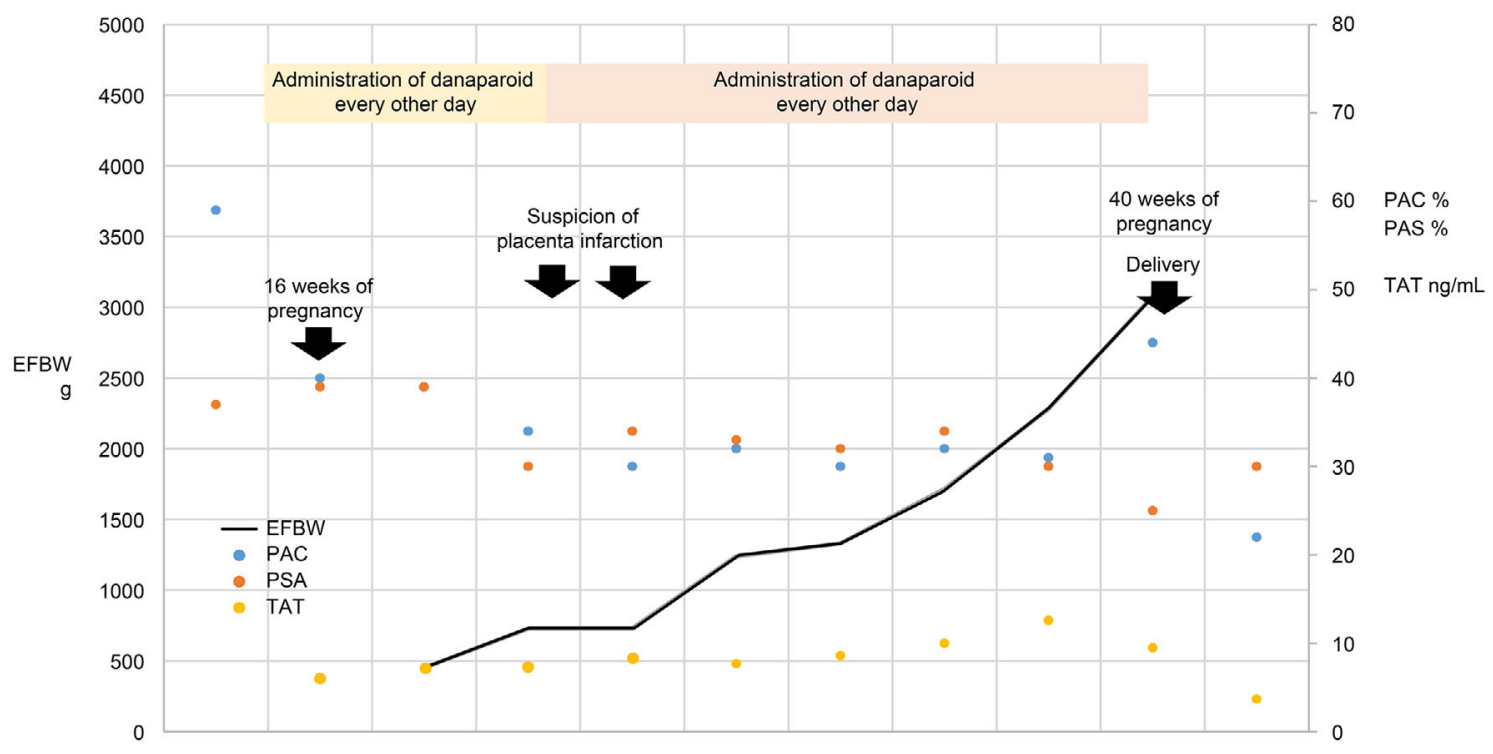

Figure 3. Clinical course of Case 2.

Table 2. Results of the Coagulation Test of Case 1.

\begin{tabular}{lcc}
\hline & Normal range \\
\hline TT & $(70-100)$ & $62 \%$ \\
PT & $(80-100)$ & $100 \%$ \\
APTT & $(25-35)$ & $44.2 \mathrm{~s}$ \\
Protein C antigen & $(70-150)$ & $19 \%$ \\
Protein C activity & $(55-150)$ & $<10 \%$ \\
Protein S antigen & $(65-135)$ & $71 \%$ \\
Protein S activity & $(60-150)$ & $55 \%$ \\
ATIII & $(79-121)$ & $89 \%$ \\
FDP & $(<10)$ & $3.8 \mu \mathrm{g} / \mathrm{mL}$ \\
D-dimer & $(<1.0)$ & $0.6 \mu \mathrm{g} / \mathrm{mL}$ \\
Thrombomodulin & $(<4.5)$ & $2.6 \mathrm{FU} / \mathrm{mL}$ \\
Plasminogen & $(80-120)$ & $61 \%$ \\
Antiplasmin & $(85-115)$ & $89 \%$ \\
$\beta$ Thrombogloblin & $(<50)$ & $186 \mathrm{ng} / \mathrm{mL}$ \\
PAI-1 & $(<50)$ & $16.1 \mathrm{ng} / \mathrm{mL}$ \\
tPA & $(<10)$ & $2.6 \mathrm{ng} / \mathrm{mL}$ \\
\hline
\end{tabular}

TT: thrombotest, PT-T: prothrombin time, PT: prothrombin, ATPP: activated partial thromboplastin time, FDP: fibrin degradation product, AT-III: antithrombin III, PAI-1: plasminogen activator inhibitor-1, tPA: tissue plasminogen activator

other day beginning at week 14 of her pregnancy. Around week 25, a periodic coagulation test showed elevated thrombin-antithrombin (TAT) and D-dimer levels. The fetal body weight estimated via ultrasonography suggested possible fetal growth retardation, and a fetal infarction was suspected. The dosing schedule of danaparoid sodium was therefore switched from every other day to once per day. Despite fluctuations in TAT and D-dimer levels, the patient did not develop thrombosis and gave birth normally to a male infant weighing $2,490 \mathrm{~g}$ on day 1 of week 40 of her pregnancy.
Patient III-1 started receiving warfarin on postpartum day 5; however, this treatment was discontinued 1 month later owing to rapid improvements in her TAT and D-dimer levels. Thrombosis screening performed at a later date revealed a heterozygous PC deficiency in the infant. The clinical course of case 2 is shown in Fig. 3.

\section{Case 3}

Patient III-2 (the elder sister of patient III-1, Fig. 1) was diagnosed with PC deficiency in 2001. She visited our hospital in May 2005, at which time she was 24 years old and 9 weeks and 5 days pregnant. The obstetrician in charge was aware of her predisposition to thrombosis and had handled her sister's pregnancy and delivery. She therefore started receiving danaparoid sodium (1,250 units, subcutaneous, every other day) when she was 15 weeks pregnant; written informed consent for this treatment was obtained.

Although the patient's TAT and D-dimer levels were occasionally elevated, she did not develop thrombosis and gave birth normally to a female infant weighing 2,614 g on day 4 of week 39 of her pregnancy. She started receiving warfarin on postpartum day 4; warfarin was discontinued about 6 weeks later owing to normalization of her coagulation system and TAT and D-dimer levels. The clinical course of case 3 is shown in Fig. 4.

\section{Discussion}

Anticoagulant deficiencies are sometimes triggered by factors such as surgery, cancer, pregnancy, and specific medications. They increase the risk of blood clots in the veins and spur production of immense blood clots throughout the entire arteriovenous system (11). PC and PS (but not AT-III) deficiencies also increase the risk of arterial blood clots in individuals aged $<55$ years (12). Hereditary anticoagulant deficiencies thus require our attention. 


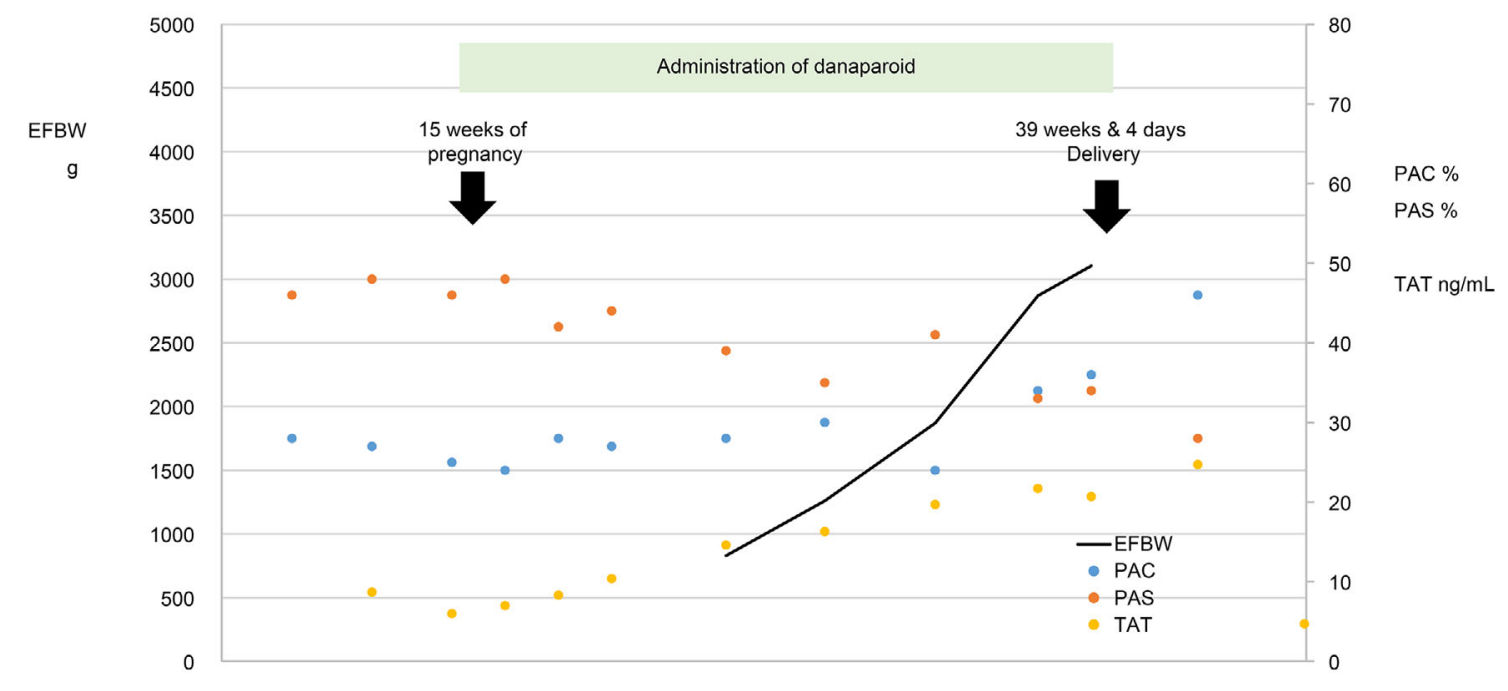

Figure 4. Clinical course of Case 3.

The proband patient (II-2, Fig. 1) developed systemic venous and arterial thrombosis. He also had antiphospholipid antibody syndrome, an immune deficiency that adversely affects the clinical course of thrombosis, making it more severe (13). Furthermore, central arterial occlusion, perhaps due to the thrombosis, led to blindness in his right eye (14).

PC deficiency was not detected in the proband's mother (Fig. 1, I-1) on genetic screening for thrombosis predisposition. Although she exhibited antinuclear antibody positivity, she had no history of miscarriage or symptoms of thrombosis. The proband's father (Fig. 1, I-2) died immediately after abdominal surgery. A potential cause of his death was postoperative thrombosis due to PC deficiency and the stress of surgery. However, we cannot confirm this because he was not autopsied or tested for a genetic predisposition to thrombosis.

Five family members (Fig. 1; II-2, II-4, III-1, III-2, and III-3) had a heterozygous mutation (L223F) in the gene encoding PC (PROC). This mutation, which characterizes type I PC deficiency, reduces the activity and amount of PC. Most type I-associated missense mutations either replace internal hydrophobic residues (I201T, L223F, A259V, A267T, A346T, A346V, and G376D) or nearby interacting residues (I403M, T298M, and Q184H) (15). We also analyzed the coding sequence of the PROS gene (which encodes PS), but no mutations were detected.

Thrombosis during pregnancy can cause developmental delays or death of the fetus. In addition, thrombosis in the mother also increases the risk of thrombosis in the fetus (7). Predisposition to blood clotting is more common in pregnant women than is generally recognized. Antithrombotic treatment of thrombophilic women with recurrent pregnancy loss is effective (16). Owing to their PC deficiency, the pregnant women (Fig. 1, III-1 and III-2) in our study were comanaged by the personnel in two departments (Pediatrics and Internal Medicine) in our hospital in case emergency situations developed. Based on existing reports $(17,18)$ and the present study, we strongly recommend anticoagulant screening in women who are planning to become pregnant.

Studies describing the results of genetic screening in multiple family members with long-term follow-ups at a single hospital are rare. In this period, we reaffirmed that hereditary disorders are not only a health concern for the person but can be inherited by descendants. All family members mentioned in our study (except 1 and 2, who died; Fig. 1) provided their written informed consent for genetic screening, and interactions between them and the hospital personnel were pleasant. We consider our experience in this endeavor to be invaluable, as it overcame medical barriers.

Except for the proband, all family members with PC deficiency were in good condition, without serious thrombotic symptoms, including the two women who became pregnant after the carrier screening. Owing to the good quality of their treatment and the teamwork of the medical staff at our hospital, these women safely gave birth. These two pregnant women were fortunate that they did not develop antiphospholipid syndrome; otherwise, they might have suffered serious complications similar to that of the proband. Women diagnosed with anticoagulant deficiency tend to believe that they can successfully bear children. Obstetricians, hematologists, and thrombosis experts should therefore act in a concerted and upbeat manner to determine the appropriate treatment for such women during and after pregnancy (19).

According to a recent study, mutations in the PROC and PROS genes and consequent malfunctions in PC and PS account for thrombosis predisposition in most Asians (6). Therefore, screening for disease-associated gene mutations is performed worldwide, sometimes on a commercial basis. Identifying such mutations can lead to promising gene therapies, although gene therapies are not free from problems and difficulties (20). Despite their importance in predicting the risk of thrombosis, thrombosis screening is sometimes performed after symptoms have developed. Offering carrier screenings to the general public may help remedy this situ- 
ation. It may also prevent serious thrombosis-related complications not just in individuals but also in their family members as well as future generations $(21,22)$. Most people are unaware of the genetic risk of thrombophilia and its potentially dire consequences (23). We strongly hope that hereditary thrombosis carrier screening will significantly benefit the general population and that our report will be of value to clinicians.

The authors state that they have no Conflict of Interest (COI).

\section{Acknowledgement}

The authors would like to express their appreciation to the late Dr. Haruo Yamada for his many years of insightful comments and support for this study.

\section{References}

1. Green ED, Watson JD, Collins FS. Human Genome Project: Twenty-five years of big biology. Nature 526: 29-31, 2015.

2. Harper JC, Aittomaki K, Borry P, et al. Recent developments in genetics and medically assisted reproduction: from research to clinical applications. Eur J Hum Genet 26: 12-33, 2018.

3. Clarke AJ, Wallgren-Pettersson C. Ethics in genetic counselling. J Community Genet 10: 3-33, 2019.

4. Previtali E, Bucciarelli P, Passamonti SM, Martinelli I. Risk factors for venous and arterial thrombosis. Blood Transfus 9: 120$138,2011$.

5. D'Uva M, Di Micco P, Strina I, et al. Etiology of hypercoagulable state in women with recurrent fetal loss without other causes of miscarriage from Southern Italy: new clinical target for antithrombotic therapy. Biologics 2: 897-902, 2008.

6. Abraitis V, Simoliūniene R, Mongirdiene A, Makari S. Prevalence of activated protein $\mathrm{C}$ resistance among women with recurrent miscarriage. Medicina (Kaunas) 40: 225-231, 2004.

7. Croles FN, Nasserinejad K, Duvekot JJ, Kruip MJ, Meijer K, Leebeek FW. Pregnancy, thrombophilia, and the risk of a first venous thrombosis: systematic review and Bayesian meta-analysis. BMJ 359: j4452, 2017.

8. Giofrè MC, Napoli F, La Rosa D, et al. Recurrent thrombosis: a case of hereditary thromboembolism. Am J Case Reports 18: 1157-1159, 2017

9. Xie W, Liu Z, Chen B. Protein C deficiency resulting from two mutations in PROC presenting with recurrent venous thromboembolism. J Vasc Surg Cases Innov Tech 3: 254-256, 2017.

10. Hamasaki N. Unmasking Asian thrombophilia: is APC dysfunction the real culprit? J Thromb Haemost 10: 2016-2018, 2012.

11. Lijfering WM, Brouwer JL, Veeger NJ, et al. Selective testing for thrombophilia in patients with first venous thrombosis: results from a retrospective family cohort study on absolute thrombotic risk for currently known thrombophilic defects in 2479 relatives. Blood 113: 5314-5322, 2009.

12. Mahmoodi BK, Brouwer JL, Veeger NJ, van der Meer J. Hereditary deficiency of protein $\mathrm{C}$ or protein $\mathrm{S}$ confers increased risk of arterial thromboembolic events at a young age: results from a large family cohort study. Circulation 118: 1659-1667, 2008.

13. Kremers RMW, Zuily S, Kelchtermans H, et al. Prothrombin conversion is accelerated in the antiphospholipid syndrome and insensitive to thrombomodulin. Blood Adv 2: 1315-1324, 2018.

14. Kida T. Mystery of retinal vein occlusion: vasoactivity of the vein and possible involvement of endothelin-1. BioMed Res Int 2017: 4816527, 2017.

15. Greengard JS, Fisher CL, Villoutreix B, Griffin JH. Structural basis for type I and type II deficiencies of antithrombotic plasma protein C: patterns revealed by three-dimensional molecular modelling of mutations of the protease domain. Proteins 18: 367-380, 1994.

16. Brenner B, Huffman R, Carp H, Dulitsky M, Younis J. Efficacy and safety of two doses of enoxaparin in women with thrombophilia and recurrent pregnancy loss: the LlVE-ENOX study. J Thromb Haemost 3: 227-229, 2005.

17. Ohga S, Ishiguro A, Takahashi $Y$, et al. Protein $C$ deficiency as the major cause of thrombophilias in childhood. Pediatr Int 55: 267271,2013

18. Kim S, Song I, Kim HK, Huh S. Thrombophilia in Korean patients with arterial or venous thromboembolisms. Ann Surg Treat Res 90: 340-345, 2016.

19. Linnemann B, Scholz U, Rott H, et al. Treatment of pregnancyassociated venous thromboembolism-position paper from the Working Group in Women's Health of the Society of Thrombosis and Haemostasis (GTH). Vasa 45: 103-118, 2016.

20. Joly BS, Coppo P, Veyradier A. Thrombotic thrombocytopenic purpura. Blood 129: 2836-2846, 2017.

21. Lee SY, Kim EK, Kim MS, et al. The prevalence and clinical manifestation of hereditary thrombophilia in Korean patients with unprovoked venous thromboembolisms. PLOS One 12: e0185785, 2017.

22. Martin-Fernandez L, Gavidia-Bovadilla G, Corrales I, et al. Next generation sequencing to dissect the genetic architecture of KNG1 and F11 loci using factor XI levels as an intermediate phenotype of thrombosis. PLOS One 12: e0176301, 2017.

23. Sennblad B, Basu S, Mazur J, et al. Genome-wide association study with additional genetic and post-transcriptional analyses reveals novel regulators of plasma factor XI levels. Hum Mol Genet 26: $637-649,2017$.

The Internal Medicine is an Open Access journal distributed under the Creative Commons Attribution-NonCommercial-NoDerivatives 4.0 International License. To view the details of this license, please visit (https://creativecommons.org/licenses/ by-nc-nd/4.0/).

\section{(C) 2019 The Japanese Society of Internal Medicine} Intern Med 58: 1923-1928, 2019 